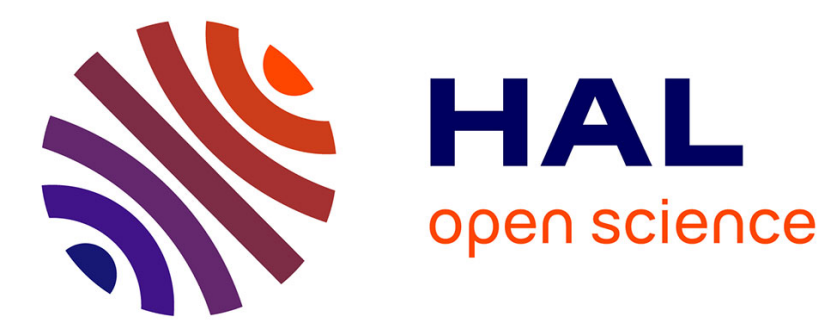

\title{
Measurement of pull-off force for planar contact at the microscale.
}

Kanty Rabenorosoa, Cédric Clévy, Philippe Lutz, Michaël Gauthier, Patrick

Rougeot

\section{- To cite this version:}

Kanty Rabenorosoa, Cédric Clévy, Philippe Lutz, Michaël Gauthier, Patrick Rougeot. Measurement of pull-off force for planar contact at the microscale.. Micro and Nano Letters, 2009, 4 (3), pp.148-154. 10.1049/mnl.2009.0034 . hal-00417663

\section{HAL Id: hal-00417663 https://hal.science/hal-00417663}

Submitted on 16 Sep 2009

HAL is a multi-disciplinary open access archive for the deposit and dissemination of scientific research documents, whether they are published or not. The documents may come from teaching and research institutions in France or abroad, or from public or private research centers.
L'archive ouverte pluridisciplinaire HAL, est destinée au dépôt et à la diffusion de documents scientifiques de niveau recherche, publiés ou non, émanant des établissements d'enseignement et de recherche français ou étrangers, des laboratoires publics ou privés. 


\title{
Measurement setup of pull-off force for planar contact at the microscale
}

\author{
*Kanty Rabenorosoa, Cédric Clévy, Philippe Lutz, Michaël Gauthier, Patrick Rougeot \\ FEMTO-ST Institute, UMR CNRS 6174 - UFC / ENSMM / UTBM, \\ 24 rue Alain Savary, 25000 Besançon, France \\ Phone: +33 (0)3 814028 54, fax: +33 (0)3 814028 09, \\ E-mail: rkanty@femto-st.fr
}

\begin{abstract}
During micro-assembly processes, surface forces influence the behavior of micro-objects more than volumic forces. Generally contacts happen between a microgripper and a micro-objet or a substrate and a micro-object. The pull-off force which represents the force required to break a contact is one of the predominant problem in micro-assembly. Now, current force measurements are mostly focused on sphere-plane geometries and models are based on nanoscale theories. The aim of this article is to propose a measurement setup able to evaluate the pull-off force for a planar contact (most frequent kind of contact in micro-assembly). Experimental force measurements based on a capacitive microforce sensor and micro/nano robotic system are carried out. The proposed device enables the study of pull-off forces according to the preload force and the contact angle. Finally experimental results are discussed and compared with a model.
\end{abstract}

\section{Introduction}

Miniaturisation in the field of telecommunication and sensor technology is increasing and requires to manufacture highly complex 3D hybrid and intelligent microsystems by the assembly of varied microparts [1]. Indeed the possibility to assemble complex and varied microsystems is in current investigation and already shows promising results [2], [3], [4]. Micro-assembly constitutes new challenges according to size and specificities of micro-parts in reference to [5], [6], [7] and adapted tools are under development (visual servoing [8], force measurement [9], control strategies [10], 
microrobots [11] etc.). During robotic micro-assembly, microparts have to be picked, moved, and released. Other tasks like insertion, alignment and guiding can also be done. A contact between two surfaces, for example, gripping tools and a manipulated object or a substrate and a manipulated object generates adhesion forces. The force required to separate two surfaces is commonly called "pull-off". Behaviors of the microparts in contact requires deep knowledge to succeed in micro-assembly operations [12], [13].

Silicon is a widespread material in hybrid assembly and the contact between the tools and the manipulated object or the substrate and the manipulated object are generally silicon/silicon planar contacts [2], [3], [14]. Several models have been developed for a contact between a sphere and a planar surface. They are mainly based on Johnson-Kendall-Roberts (JKR) [15] or Derjaguin-Muller-Toporov (DMT) formulations [16]. Moreover, the current methods to measure micro-nanoforces between surfaces are the Surface Force Apparatus (SFA), and the Atomic Force Microscope (AFM). The SFA enable the measure of forces between typically two cylinders or between a sphere and a planar surface $[17,18]$. The AFM are used to measured forces in the case of sphere-plan contact where the force is typically from nanonewtons to several micronewtons [19], [20], [21], [22], [23]. As these types of contacts (cylinder-cylinder and sphere-plan) do not require a precise relative angular position, in both measurement devices (SFA and AFM) the angles of surfaces are not precisely controlled. In the case of a micrometric planar contact, the orientation between two surfaces is the main critical point and the pull-off force could reach several hundreds of $\mu N$. New measurement devices must be studied in order to investigate pull-off force between planar microscopic surfaces [24].

Currently, the increase of the understanding between both planar surface requires (i) the study and the design of new microforce measurement devices able to characterize pull-off forces on these geometries, (ii) the study of multiphysic models which take into account interatomic forces and the mechanical deformation of the contact [25].

In this paper, we propose an experimental setup that enables the characterization of pull-off forces between two planar silicon surfaces $(50 \mu m \times 50 \mu m)$. This setup is based on several microrobotic stages and a capacitive microforce sensor. Section 2 presents the experimental setup. The influence of the preload force and contact's angle are studied and experimental results are presented in section 3. Discussions on results and a comparison with a model are proposed in section 4. Finally, conclusions and more general discussions on the consequences of pull-force on micro-assembly are presented. 


\section{Measurement setup}

The objective of this setup is the measurement of the pull-off force for a planar silicon/silicon contact. The capability to ensure the relative orientation of both surfaces is the main criteria for performing the pull-off force measurement. In this case, two angles have to be controlled. The generation of a linear motion perpendicular to the planar surfaces must then be ensured to allow an approach/retract between both surfaces. A fine positioning stage ensures the control of the preload force as well as this linear approach/retract motion. The roughness of both surfaces, the velocity during approach and retract, contact duration, temperature, humidity can influence the amplitude of the pull-off force. In the following, a proposed measurement setup is detailled.

Force measurement is done by a capacitive force sensor from FemtoTools ${ }^{1}$. The one used is a S270 probe type with $2 \mathrm{mN}$ in range, $0.4 \mu N$ resolution and $1000 \mathrm{~N} / \mathrm{m}$ stiffness. It generates an output voltage linear to the applied force in the sensitive direction. The maximum displacement of the probe according to the stiffness is limited to $2 \mu \mathrm{m}$. Sensors are individually calibrated by the manufacturer.

For ensuring the planar contact, a micro/nano robotic system has been developped. The coarse positioning stages ensure a first relative positioning of both surfaces. Fine positioning stages ensure the precise control of the angular contact and linear motion which is perpendicular with the planar surface during approach/rectract. This positioning system comprises two main subsystems (see Figure 1):

- A robotic system (Subsystem 1) composed of a fine positioning robot with four Degrees Of Freedom - DOF $x_{1}$, $y_{1}, z_{1}$ and $\theta$ based on Physik Instrumente P-611.3 NanoCube XYZ Piezo Stage with integrated sensor (100 $\mu \mathrm{m}$ of stroke and $1 \mathrm{~nm}$ of resolution) and a sensorized rotation stage SmarAct SR-3610-S (1.1 $\mu^{\circ}$ of resolution). Both of these fine positioning systems are closed loop controlled. They are mounted on a three DOF coarse positioning stage. This subsystem enables the displacementof the microforce sensor fixed on it.

- A silicon surface also called sample is fixed on a rigid beam after being cleaned with a mixture of sulfuric acid and hydrogen peroxide. The beam is mounted on a closed loop controlled rotation stage SmarAct SR3610-S. This stage allows control of the angle along the $\mathrm{Y}$ axis $(\varphi)$. They are mounted on a three DOF coarse positioning stage (Subsystem 2).

The tip of the force sensor's probe and the sample constitute both planar surfaces that will be in contact (see Figure 2). The size of the contact is $50 \mu m \times 50 \mu m$ which is the square surface of the tip. The roughness of surfaces in contact influence the amplitude of pull-off forces. Thus, the roughness measurements for FemtoTools probe and

\footnotetext{
${ }^{1}$ FemtoTools is a Swiss company. http://www. femtotools.com/
} 


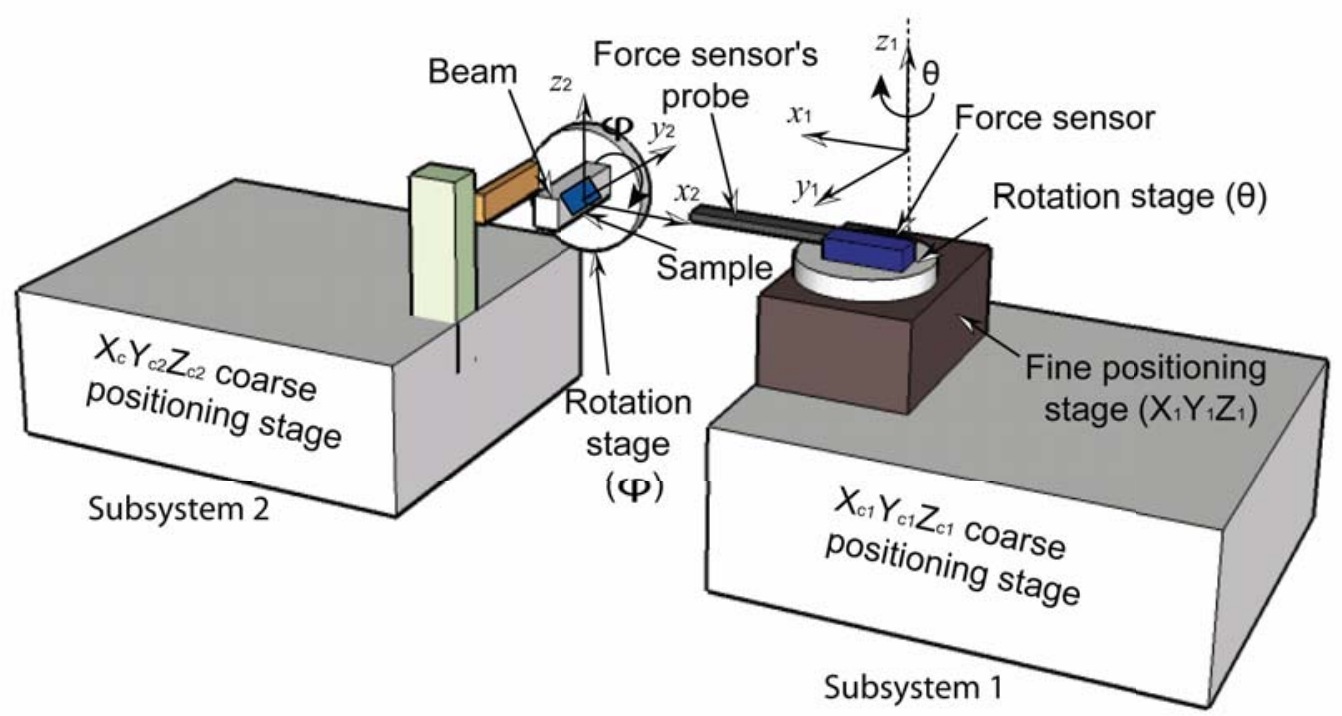

Figure 1: Configuration of the measurement setup.

the sample are made by AFM and depicted on the Figure 3. The rms (root mean square) roughness $\left(R_{q}\right)$ of the probe (surface 1) is $24.31 \mathrm{~nm}$ and the maximum peak to peak roughness $\left(R_{t}\right)$ is $163 \mathrm{~nm}$. This surface roughness is typically obtained for the vertically etched sidewall in silicon. Indeed, DRIE (Deep Reaction Ion Etching) process employs cyclic etching and deposition steps to achieve high aspect silicon structures and sidewall scalloping is observed. This kind of surface is usually used during micro-assembly process. The rms roughness $\left(R_{q}\right)$ of the sample (surface 2$)$ is $6.60 \mathrm{~nm}$ and the maximum peak to peak roughness $\left(R_{t}\right)$ is $31 \mathrm{~nm}$. This sample is a part with surface etched by DRIE which is often used in the fabrication of microcomponents used for micro-assembly.

A velocity along a normal direction to both surfaces is fixed at $800 \mathrm{~nm} / \mathrm{s}$ during approaching and retracting. The experimental setup for the pull-off force measurements is depicted on the Figure 2.

\section{$3 \quad$ Experimental results}

During the experimentation, the measured humidity is between 35 to $45 \%$ and the temperature is between 24 to 28

${ }^{\circ} \mathrm{C}$. Using the proposed measurement device, typival curves of the approach/retract can be obtained (see Figure 4).

The stiffness of the force sensor is observed on the approach/retract curve (Stiffness of $K_{\text {sensor }}=1000 \mathrm{~N} / \mathrm{m}$ ). The preload force is the maximum force according to the displacement. The pull-off force is identified as the jump-off 


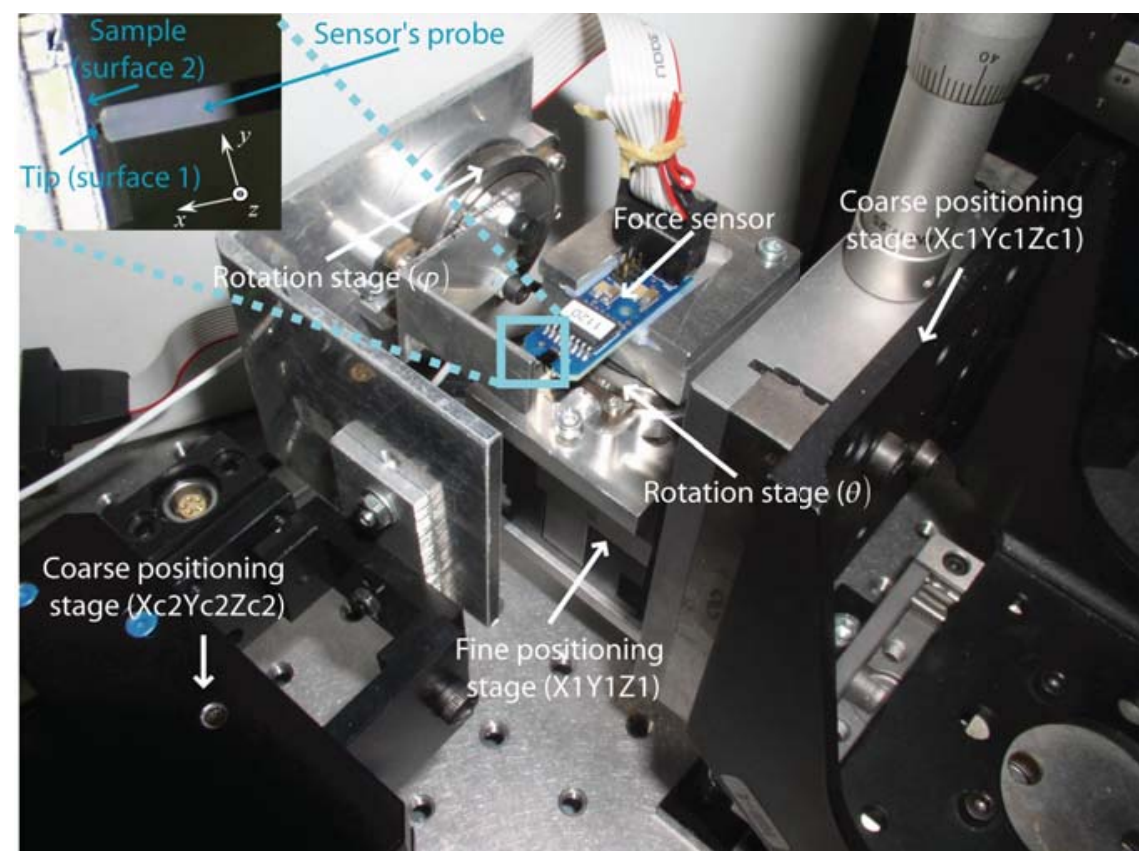

Figure 2: Experimental setup for pull-off force measurement. The pull-off force between surface 1 (tip of the probe) and surface 2 (sample) is mesured along axis $\mathrm{X}$ (direction normal to the planar contact)

(a)

(b) $\quad \mathrm{Rt}=163 \mathrm{~nm}, \mathrm{Rq}=24.31 \mathrm{~nm}$
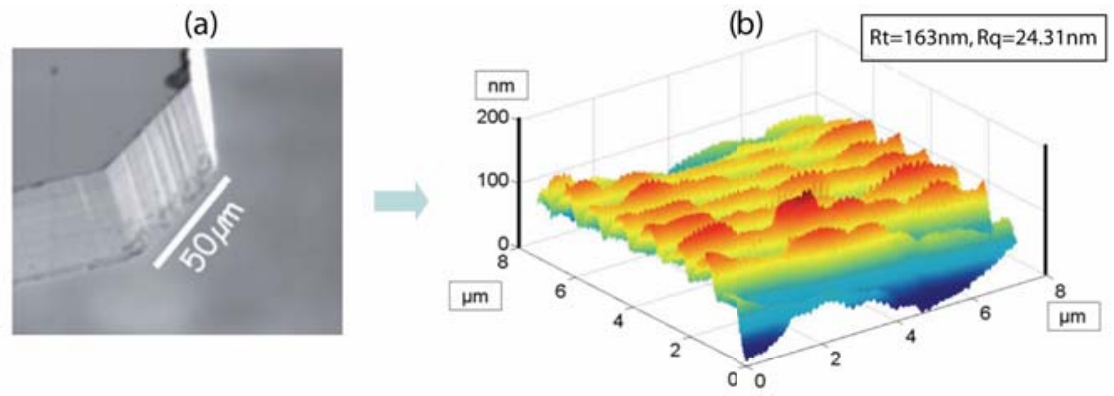

(c)

$\mathrm{Rt}=31 \mathrm{~nm}, \mathrm{Rq}=6.60 \mathrm{~nm}$

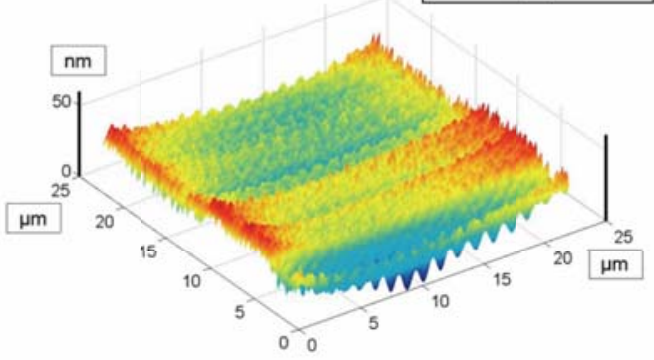

Figure 3: (a) SEM view of the planar surface at the tip of the force sensor's probe, (b) Roughness measurement of the tip, (c) Roughness measurement of the sample. 


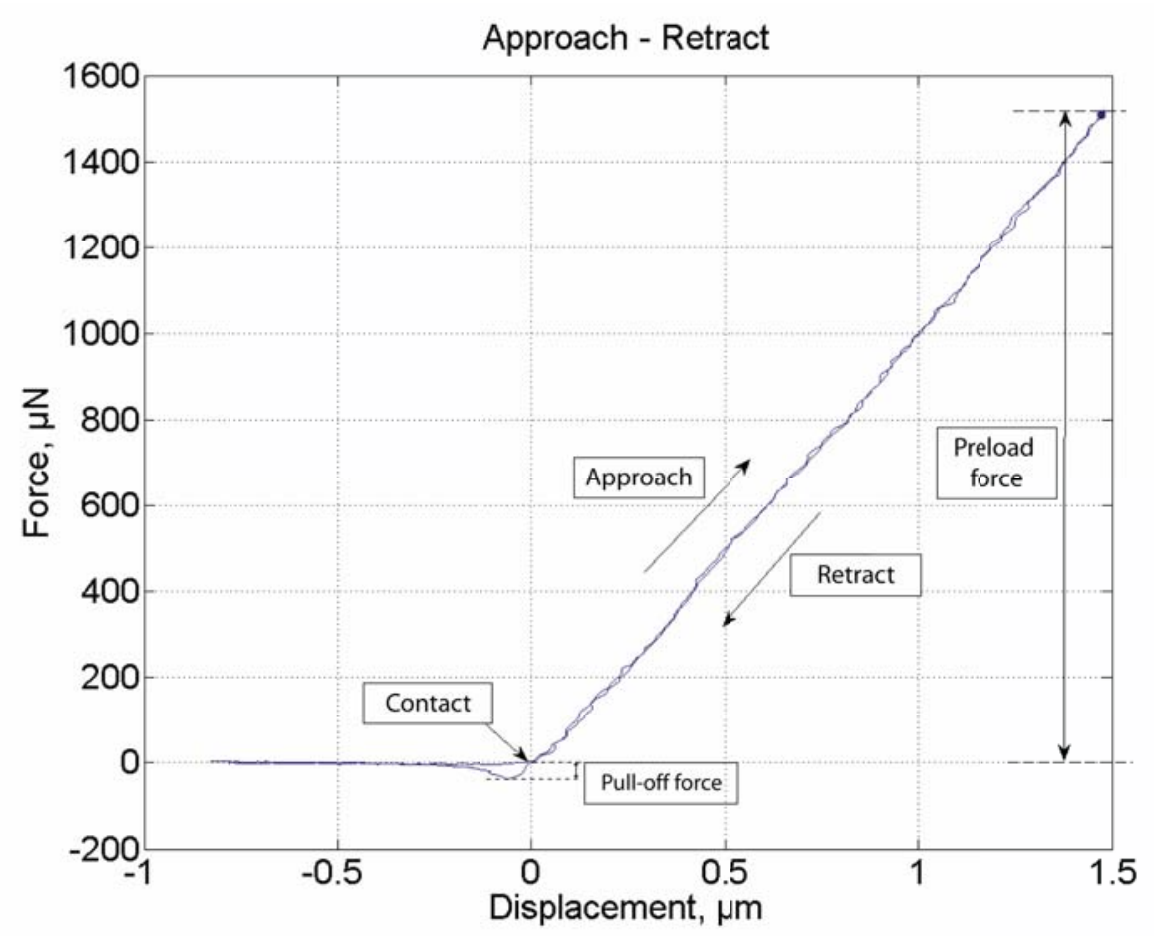

Figure 4: Typical curve for approach/retract between both planar surfaces.

behavior. The measurement procedure is validated according to a variability of the measurements of pull-off force smaller than $20 \%$ (with fixed experimental parameters). In the same way, the measurement of the pull-off force is very repeatable in different contact points on the same sample. These results validate the measurement setup and the measurement procedure.

Several measurements are done with different variation of parameters (contact angle, preload, velocity). First results show that pull-off forces vary in the range of 0 to $196 \mu N$. Thus the pull-off force is predominant at the microscale especially for micro-assembly tasks:

- Considering a silicon component of $1000 \mu m \times 800 \mu m \times 200 \mu m$, its weight is $4 \mu N$ an the gripping force to apply on this component has to be in the range of $20 \mu N$.

- The SNR (signal-to-noise ratio) is important (pull-off force up to $196 \mu N$ and force noise smaller than $10 \mu N$ - SNR $(d B)=25.8 d B)$ leading to the possibility of estimating pull-off force and using it on advanced control strategies.

Next subsections deal with the influence of the main parameters: angle $\theta$ and preload force. 


\subsection{Angle effect}

The effect of the angle has been studied. In this part, the preload force is maintained around $200 \mu N$ and the fixed velocity is used $(800 \mathrm{~nm} / \mathrm{s})$. Once the angle $\varphi$ fixed (motorized rotation to maximize the pull-off force), the probe's angle $(\theta$ - as defined in Figure 1$)$ is then precisely controlled and varies to get the effect of the contact's angle. The variation of pull-off force according to $\theta$ is shown in Figure 5.

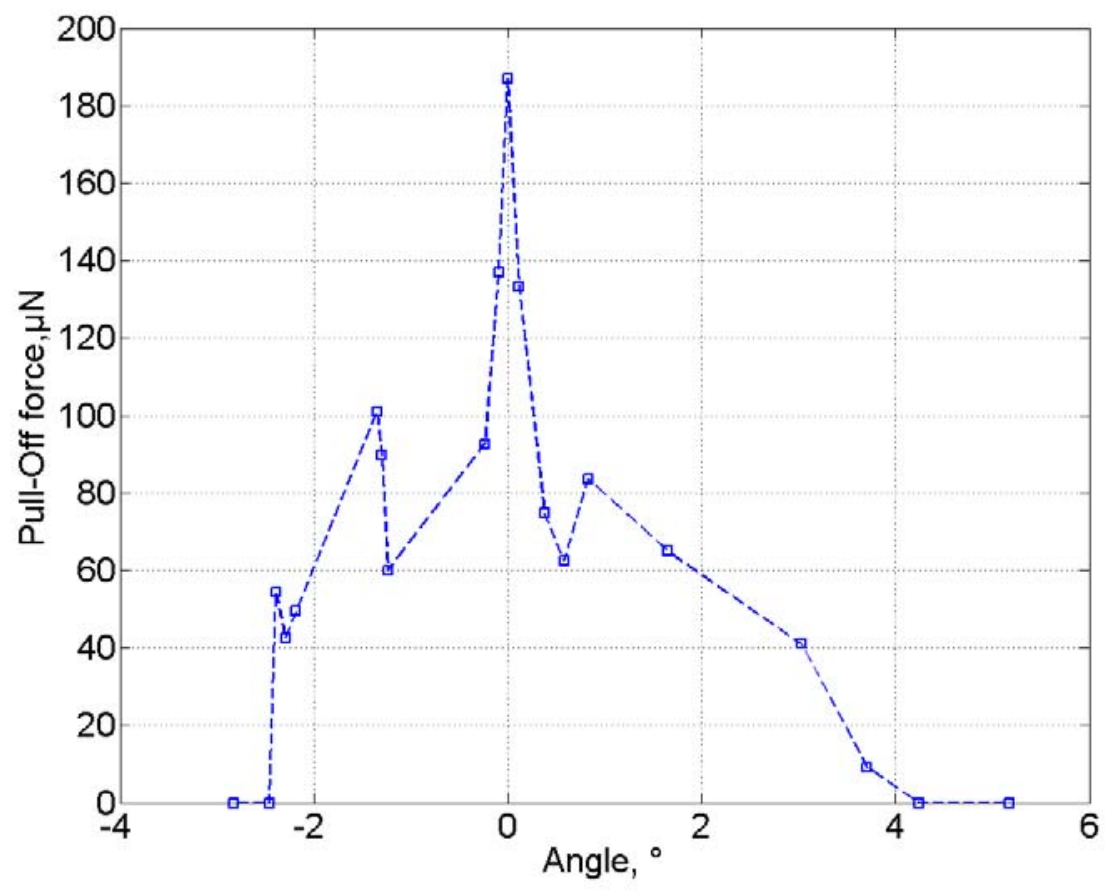

Figure 5: Angle $(\theta)$ effect in pull-off force measurement.

The contact's angle influences the amplitude of the pull-off force. The variation of pull-off force is between $0 \mu N$ to $196 \mu N$. We can assume that the maximum pull-off force correponds to a perfect planar contact. We can see in this curve that deviating from a few tens of milli degrees of perfect contact notably decreases the magnitude of the pull-off force. This result is important in the application field of micro-assembly. Indeed the pull-off force between two microparts (guiding task/ assembly) or a microgripper and a micropart (pick and place) can be volontary reduced by controlling for example their contact's angle. 


\subsection{Preload effect}

The study of the preload effect has been investigated too. Both surfaces are aligned using the scanning of the angle $\theta$ and $\varphi$. Different preload forces are applied with the fine positioning stage. The measurement procedure is applied with the same approach/retract velocity $(800 \mathrm{~nm} / \mathrm{s})$ as for the angle effect study. The results are shown in Figure 6 .

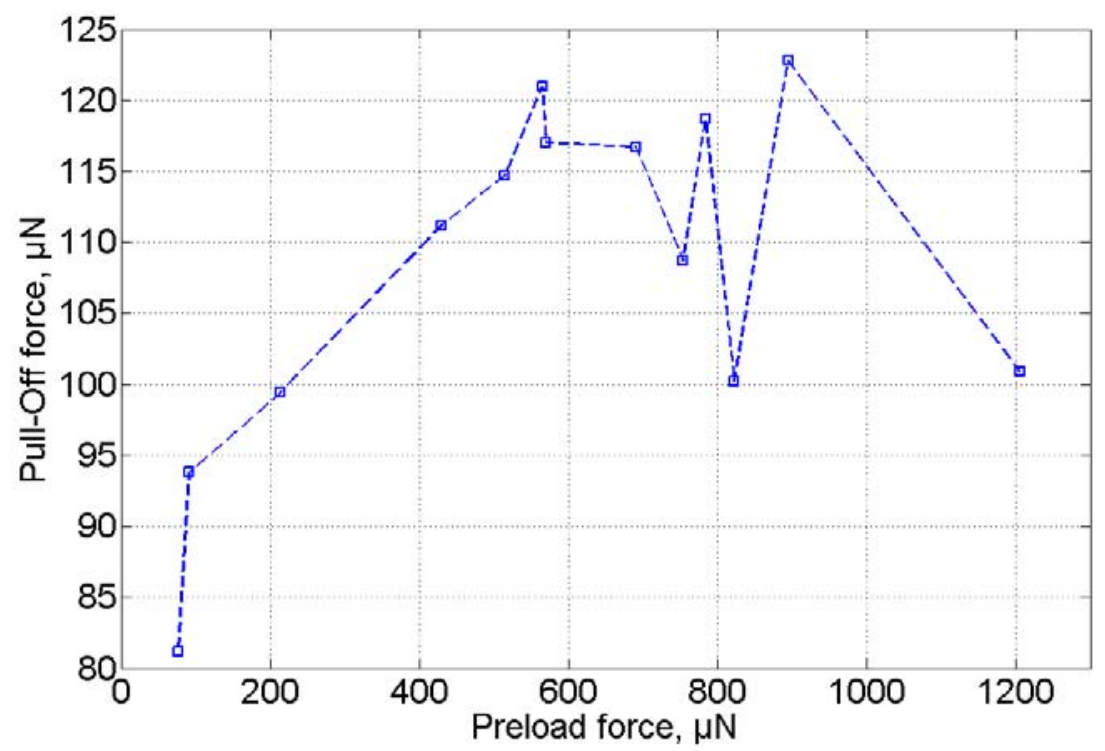

Figure 6: Pull-off force variation according to preload force.

These results show that the preload weakly influence the pull-off force (peak to peak - $34 \%$ of variation). We can assume that the plastification and the indentation between both surfaces do not occur (Cf. Section 4). As a consequence, pull-off force can be evaluated during the micro-assembly process. This result is very helpful in the developpement of strategies in micro-assembly. Due to this specificity, where devices are often compliant (gripping tools, objects, actuators, contact sensors), pull-off force can induce unwanted displacements for micrometric components. Pull-off force has to be controlled (or at least to be evaluated) to achieve an accurate positioning required to succeed micro-assembly tasks. 


\section{Discussions}

\subsection{Comparison of experimental results with theoretical expressions}

The experimental force measurements presented in this article can be compared to interaction forces expressed in the literature. Adhesion forces are induced by interaction forces such as van der Waals forces and capillary forces between two surfaces [31], [32]. The measured pull-off force can compared to its constituants: the surface van der Waals forces and the capillary forces. Analytic expression of the capillary forces is available in the literature [12] but they don't take into account the effect of the surface roughness. Analytic expression of the surface van der Waals force $f_{v d w}$ between two infinite planes is proposed in the literature [27]:

$$
f_{v d w}=\frac{A}{6 \pi z^{3}}
$$

where $A$ is the Hamaker constant and $z$ the distance between both planes which is typically $0.3 \mathrm{~nm}$.

As the typical length of the surface $(50 \mu m)$ is greater than the distance $z$, we assume that the van der Waals force $F_{v d w}$ between both surfaces is proportional to the surface $S$ [25]:

$$
F_{v d w}=\frac{A . S}{6 \pi z^{3}}
$$

The roughness of the surface cannot be neglected according to [28]. Several models exist to quantify the impact of the roughness on van der Waals forces. For example, [29] proposed the following model:

$$
F_{v d w}^{r o u g h}=\left(\frac{z}{z+\frac{R_{t}}{2}}\right)^{2} \cdot F_{v d w}
$$

where $R_{t}$ represents the maximum height of the rough profile. The roughness measurements permit to estimate $R_{t}$ $=163 \mathrm{~nm}$.

The Hamaker constant $A$ between both silicon surfaces is between 143 and $173 z J$ [30], thus the theoretical van der Waals force can be calculated:

$$
F_{v d w}^{r o u g h} \in[9 ; 11] \mu N
$$

Measured pull-off forces (presented in Section 3) reach $196 \mu N$ which are largely bigger than the theorical estimation of the van der Waals forces. These forces always exist and represent a part of the forces that constitute the 
adhesion forces. Moreover, the model (3) used to determine the impact of the roughness stay an approximation and further modeling studies should be investigated.

\subsection{Surface force}

The van der Waals force between both planes can be considered as a surface force $f_{v d w}$ applied on the surface $S$. In our experiments, the measured surface forces $f_{v d w}^{e x p}$ reach :

$$
f_{v d w}^{e x p}=78.4 k P a
$$

This value represents the critical "pressure" to apply to the surface to break the contact. Moreover, the experimental pressure is negligible compared to the yield strength of the silicon (typically: $120 \mathrm{MPa}$ ). This low pressure is not able to induce a plastic deformation on the surface explaining why the preload force does not influence much the measured pull-off force.

\section{Conclusion}

In this work, a setup measurement of pull-off force for planar silicon/silicon contact is presented. It is mainly constituted by a coarse/fine microrobotic system and a capacitive microforce sensor. The tip of the sensor's probe $(50 \mu m \times 50 \mu m)$ is in contact with a cleaned sample. The influence of two parameters has been characterized: preload force and contact's angle. It was shown that preload force does not influence much pull-off force. Conversely, contact's angle variation significantly influences pull-off force. The pull-off force can reach $196 \mu N$ with the two considered surfaces and a value of probe's angle bigger than $4^{\circ}$ reduces it considerably.

In micro-assembly, planar silicon/silicon contacts often happen between micro-objects and grippers or micro-objects to assemble together. For succeeding micro-assembly operations, these results constitute helpful knowledge. Indeed, automated pick and place operations can be improve by adopting strategies which take into account the angle effect. It is also possible to develop new control strategies based on the observation of pull-off force.

Additional rotation (pitch of the sample) constitutes an interesting outlook to study the influence of both angles. Varied material, surface roughness, and size of the surface in contact can also be inverstigated. Finally, the effect of velocity approach/retract and contact duration can also be studied. 


\section{Acknowledgement}

This work has partially been supported by the French Région Franche Comté under the MIAAMI project, and by the French National Research Agency (ANR) under the NANOROL contract ANR-07-ROBO-0003: Nanoanalyse for micromanipulate.

\section{References}

[1] D. Tolfree and M. J. Jackson. Commercializing Micro-Nanotechnology Products. CRC Press, 2006.

[2] A.N. Das, P. Zhang, W. H. Lee, H. Stephanou, and D. Popa. $\mu^{3}$ : Multiscale, deterministic micro-nano assembly system for construction of on-wafer microrobots. IEEE International Conference on Robotics and Automation, pages $461-466,2007$.

[3] N. Dechev, W.L. Cleghorn, and J.K. Mills. Microassembly of 3-d microstructures using a compliant, passive microgripper. Journal of Microelectromechanical Systems, 13:176 - 189, 2004.

[4] Zyvex Labs US Patent, Michael Nolan. Apparatus and methods of manufacturing and assembling microscale and nanoscale components and assemblies, 2008.

[5] M. Gauthier, S. Régnier, P. Rougeot, and N. Chaillet. Forces analysis for micromanipulations in dry and liquid media. Journal of Micromechatronics, 3:389 - 413, 2006.

[6] D. O. Popa and H. E. Stephanou. Micro and meso scale robotic assembly. SME Journal of Manufacturing Processes, 6:52 - 71, 2004.

[7] V. Sariola, Q. Zhou, and H. N. Koivo. Hybrid microhandling: a unified view of robotic handling and selfassembly. Journal of Micro-Nano Mechatronics, 4(1-2), 2008.

[8] B. Tamadazte, S. Dembélé, and N. Le Fort-Piat. A multiscale calibration of a photon videomicroscope for visual servo control: Application to mems micromanipulation and microassembly. Sensors and Transducers Journal, $5: 37-52$, march, 2009

[9] F. Beyeler, S. Muntwyler, Z. Nagy, M. Moser, and B. J. Nelson. A multi-axis mems force-torque sensor for measuring the load on a microrobot actuated by magnetic fields. IEEE/RSJ International Conference on Intelligent Robots and Systems, pages 3803-3808, 2007.

[10] M. Rakotondrabe, Y. Haddab, and P. Lutz. Voltage/frequency proportional control of stick-slip micropositioning systems. IEEE Transactions on Control Systems Technology, 16:1316 - 1322, 2008. 
[11] M. Rakotondrabe, Y. Haddab, and P. Lutz. Development, modeling, and control of a micro-/nanopositioning 2-dof stick-slip device. IEEE/ASME Transactions on Mechatronics, 14:1-13, 2009.

[12] P. Lambert. Capillary Forces in Micro-assembly. Springer, 2008.

[13] J. Dejeu, P. Rougeot, M. Gauthier, and W. Boireau. Reduction of micro-object's adhesion using chemical functionalisation. Micro Nano Letters, 4:74 - 79, 2009.

[14] D. Hériban and M. Gauthier. Robotic micro-assembly of microparts using a piezogripper. In IEEE/RSJ International Conference on Intelligent Robots and Systems, pages 4042 - 4047, 2008.

[15] K. Johnson. Contact Mechanics. Cambridge University Press, 1987.

[16] B. V. Derjaguin, V. Muller, and Y. P. Toporov. Effect of contact deformations on the adhesion of particles. Journal of Colloid and Interface Science, 53:314 - 326, 1975.

[17] Deborah Leckband. Handbook of Molecular Force Spectroscopy, chapter Surface Force Apparatus Measurements of Molecular Forces in Biological Adhesion, pages 1-22. Springer US, 2008.

[18] Carlos Drummond and Philippe Richetti. Fundamentals of Friction and Wear, chapter Surface Forces Apparatus in Nanotribology, pages 15-33. Springer Berlin Heidelberg, 2007.

[19] Hans-Jürgen Butt, Brunero Cappella, and Michael Kappl. Force measurements with the atomic force microscope: Technique, interpretation and applications. Surface Science Reports, 59:1152, 2005.

[20] J.A.S. Cleaver and J.W.G. Tyrrell. The influence of relative humidity on particle adhesion - a review of previous work and the anomalous behavior of soda-lime glass. Kona, 22:9-22, 2004.

[21] Y. Ando. Effect of contact geometry on the pull-off force evaluated under high-vacuum and humid atmospheric conditions. Langmuir, 24:1418-1424, 2008.

[22] J. Jang, M. Yang, and G. Schatz. Microscopic origin of the humidity dependence of the adhesion force in atomic force microscopy. The Journal of Chemical Physics, 126:1 - 6, 2007.

[23] M. Savia, H.N. Koivo, and Q. Zhou. Evaluation of adhesion forces between arbitrary objects for micromanipulation. Journal of Micromechatronics, 3:221 - 238, 2006.

[24] A. Delettre. Influence de la précharge et du milieu sur la force de pull-off, application à la micromanipulation. Master's thesis, Université de Franche-Comté, 2008.

[25] M. Gauthier and S. Régnier. Robotic micro-assembly. IEEE Press, 2009.

[26] T. Eastman and D.M. Zhu. Adhesion forces between surface-modified afm tips and a mica surface. Langmuir, 12:2859-2862, 1996 . 
[27] B. Changa, Q. Zhou, and H. N. Koivo. Experimental study of microforces in a controlled environment. In Proceedings MICRO.tec 2003 - 2nd VDE World Microtechnologies Congress, 2003.

[28] M.P. de Boer and P.C.T. de Boer. Thermodynamics of capillary adhesion between rough surfaces. Journal of Colloid and Interface Science, 311:171185, 2007.

[29] M. C. Herman and K. D. Papadopoulos. A method for modeling the interactions of parallel flat plate systems with surface features. Journal of colloid and interface science, 142:331 - 342, 1991.

[30] Y. Ando, J. Lino, K. Ozaki, Y. Ishikawa, and T. Kitahara. Friction and pull-off force on silicon surface modified by fib. In IEEE MEMS, Workshop on An Investigation of Micro Structures, Sensors, Actuators, Machines and Systems, pages $349-353,1996$.

[31] F. Arai, D. Andou, Y. Nonoda, T. Fukuda, H. Iwata, and K. Itoigawa. Integrated microendeffector for micromanipulation. IEEE/ASME Transactions on Mechatronics, 3:17 - 23, 1998.

[32] H. Butt, K. Graf, and M. Kappl. Physics and Chemistry of Interfaces. Wiley, 2006. 